\title{
GCU
}

Glasgow Caledonian

University

University for the Common Good

\section{Discrete time domain small-signal modeling of full-bridge phase-shifted series} resonant converter

Aboushady, Ahmed; Ahmed, Khaled; Finney, Stephen; Williams, Barry

Published in:

2010 IEEE Energy Conversion Congress and Exposition (ECCE)

DOI:

10.1109/ECCE.2010.5618106

Publication date:

2010

Document Version

Author accepted manuscript

Link to publication in ResearchOnline

Citation for published version (Harvard):

Aboushady, A, Ahmed, K, Finney, S \& Williams, B 2010, Discrete time domain small-signal modeling of fullbridge phase-shifted series resonant converter. in 2010 IEEE Energy Conversion Congress and Exposition (ECCE). IEEE, IEEE Energy Conversion Congress and Exposition, Atlanta, Georgia, United States, 12/09/10. https://doi.org/10.1109/ECCE.2010.5618106

\section{General rights}

Copyright and moral rights for the publications made accessible in the public portal are retained by the authors and/or other copyright owners and it is a condition of accessing publications that users recognise and abide by the legal requirements associated with these rights.

Take down policy

If you believe that this document breaches copyright please view our takedown policy at https://edshare.gcu.ac.uk/id/eprint/5179 for details

of how to contact us. 


\title{
Discrete Time Domain Small-Signal Modeling of Full-Bridge Phase-Shifted Series Resonant Converter
}

\author{
A.A.Aboushady \\ Student Member \\ K.H.Ahmed \\ Member \\ S.J.Finney \\ B.W.Williams \\ Department of Electronic and Electrical Engineering \\ Strathclyde University, Glasgow, UK \\ Tel: +44 (0)141548 2124 Fax: +44 (0)141 5522487 \\ E-mail: ahmed.aboushady@eee.strath.ac.uk
}

\begin{abstract}
This paper provides an analytical discrete smallsignal state-space model of the phase-shift modulated series resonant converter used to obtain an explicit linearized phaseshift to output voltage transfer function. This transfer function is useful for linear closed loop control design. Initially, the effective duty-ratio to output voltage transfer function is derived. It is then proven, analytically and through results, that it is linearly related to the phase-shift to output voltage which is the main research concern. The analysis is carried out using state-plane diagrams. Small-signal state-space model representation is derived which is used for closed loop controller gain calculations. Results validate the calculated control gains based on the proposed linearized model.
\end{abstract}

Index Terms-Discrete time domain, Phase-Shift Modulation (PSM), Series Resonant Converter (SRC), Small-signal modeling.

\section{NOMENCLATURE}

$v_{g} \quad$ DC supply voltage $(\mathrm{V})$

$i_{L} \quad$ Resonant tank inductor current (A)

$v_{C} \quad$ Resonant tank capacitor voltage $(\mathrm{V})$

$v_{A B} \quad$ Inverter output voltage $(\mathrm{V})$

$v_{p} \quad$ Transformer primary voltage $(\mathrm{V})$

$v_{s} \quad$ Transformer secondary voltage $(\mathrm{V})$

$n \quad$ Transformer turns ratio

$C_{o} \quad$ Output filter capacitance $(\mu \mathrm{F})$

$v_{o}, i_{o} \quad$ Output voltage and current respectively $(\mathrm{V}, \mathrm{A})$

$R_{L} \quad$ Load Resistance $(\Omega)$

$f_{s} \quad$ Inverter switching frequency $(\mathrm{kHz})$

$f_{o} \quad$ Resonant frequency $=1 / 2 \pi \sqrt{L C}(\mathrm{kHz})$

$\delta \quad$ Phase-shift angle (rad)

$D \quad$ Duty-ratio $=T_{O N} / T_{S}$ where $T_{O N}$ is the time length where the inverter output is $+V_{g}$ and $D \leq 0.5$

$Z_{o} \quad$ Characteristic impedance $=\sqrt{L / C}(\Omega)$

$Q \quad$ Quality factor $=Z_{o} / R_{L}$

\section{INTRODUCTION}

Resonant converters have been favored over conventional PWM converters due to their low switching losses. High frequency operation is possible making them feasible for high power-to-size ratio modular power supplies. However, the non-linear control nature of resonant converters and the presence of fast resonant tank dynamics have made it difficult to model and control.

Several linearized small-signal models have been derived in the literature to provide insight for analysis, stability studies and closed loop control design. For the series resonant converter (SRC), under consideration, small-signal models have been introduced [1]-[3]. Discrete time domain models including the sampled-data modeling method have been proposed [4]-[6]. Discrete modeling and analysis techniques applicable to all types of inner feedback as well as non-inner feedback-controlled SRC were introduced [7]-[9]. The latter used the discrete modeling approach to obtain linearized SRC models in addition to linearized inner-feedback control laws. Such laws have been widely covered in the literature, like average-current control, frequency control, capacitor voltage control, diode-conduction-angle control, and optimal trajectory control. However, the aforementioned variable frequency control techniques present practical disadvantages, like a wide noise spectrum which makes it difficult to control EMI, more complex filtering, poor utilization of magnetic components, in addition to poor voltage regulation at low load [10].

Fixed-frequency modulation techniques like phase-shift modulation (PSM) [11]-[15], asymmetrical duty-cycle modulation [16], [17] and asymmetrical clamped-mode modulation [18], [19] overcome problems of variablefrequency control and offer excellent control on the output voltage. Numerous discrete time domain models for fixedfrequency phase-shifted LCC-type resonant converters have been derived [20]-[22]. However, an explicit phase-shift-tooutput voltage transfer function does not exist. This paper extends the generalized discrete time domain small-signal approach introduced in [4] to model the fixed-frequency phase-shifted SRC. The goal is to derive an explicit smallsignal phase-shift-to-output voltage transfer function which can be applied to closed loop control design. 


\section{SYSTEM DESCRIPTION}

Fig. 1 illustrates the full bridge phase-shift modulated SRC topology. Conventional duty-ratio control (Fig. 2a) implements a $180^{\circ}$ phase shift between inverter legs, whereas in the phase-shift modulation technique, all switches are on for half the switching period and the phase angle between inverter legs is controlled (Fig. 2b). A linear relationship between effective duty-ratio $(D)$ and phase shift angle $(\delta)$ exists $(\delta=2 \pi D)$ as shown in Fig.2. For this reason, the analysis will be presented in terms of $D$. For analysis simplicity, the transformer is assumed to have a unity turns ratio with the effect of its leakage inductance added to the resonant inductance. The analysis is carried out for operation above resonance, assuming continuous inductor current.

\section{STATE-PLANE ANALYSIS}

State-plane analysis of the PSM-SRC is carried out to take advantage of geometrical relations in deriving a generalized state-space model. Analysis assumes inverter output voltage half-wave symmetry. Typical waveforms for above resonance continuous mode PSM-SRC operation is shown in Fig.3a. The state-plane diagram $\left(v_{c}-i_{L}\right)$ is derived from the differential equations of each of the positive half-cycle subperiods (A-D) shown in Fig.3b.

Sub-Period $A: t_{0} \leq t \leq t_{1}$

$\frac{d i_{L}}{d t}=\frac{1}{L}\left(-v_{c}+v_{o}\right)$

$\frac{d v_{C}}{d t}=\frac{1}{C} i_{L}$

$\frac{d v_{o}}{d t}=-\frac{1}{C_{o}}\left(i_{L}+\frac{v_{o}}{R}\right)$

Sub-Period $C: t_{2} \leq t \leq t_{3}$

$\frac{d i_{L}}{d t}=\frac{1}{L}\left(-v_{c}-v_{o}+v_{g}\right)$

$\frac{d v_{C}}{d t}=\frac{1}{C} i_{L}$

$\frac{d v_{o}}{d t}=\frac{1}{C_{o}}\left(i_{L}-\frac{v_{o}}{R}\right)$

Sub-Period B: $t_{1} \leq t \leq t_{2}$ $\frac{d i_{L}}{d t}=\frac{1}{L}\left(-v_{c}+v_{o}+v_{g}\right)$ $\frac{d v_{C}}{d t}=\frac{1}{C} i_{L}$

$\frac{d v_{o}}{d t}=-\frac{1}{C_{o}}\left(i_{L}+\frac{v_{o}}{R}\right)$

Sub-Period D: $t_{3} \leq t \leq \frac{T_{S}}{2}$

$\frac{d i_{L}}{d t}=\frac{1}{L}\left(-v_{c}-v_{o}\right)$

$\frac{d v_{C}}{d t}=\frac{1}{C} i_{L}$

$\frac{d v_{o}}{d t}=\frac{1}{C_{o}}\left(i_{L}-\frac{v_{o}}{R}\right)$

Solving the sub-period equations, the $v_{c}-i_{L}$ relation can be expressed as

$\left(Z_{o} i_{L}\right)^{2}+\left(v_{c}-V_{c_{1}}\right)^{2}=V_{M_{1}}^{2}$ for $t_{0} \leq t \leq t_{1}$

where $V_{c_{1}}=V_{o}$ and $V_{M_{1}}=-V_{c_{\max }}-V_{c_{1}}$

$\left(Z_{o} i_{L}\right)^{2}+\left(v_{c}-V_{c_{2}}\right)^{2}=V_{M_{2}}^{2}$ for $t_{1} \leq t \leq t_{2}$ where $V_{c_{2}}=V_{g}+V_{o}$ and $V_{M_{2}}=-V_{c_{\max }}-V_{c_{2}}$

$\left(Z_{o} i_{L}\right)^{2}+\left(v_{c}-V_{c_{3}}\right)^{2}=V_{M_{3}}^{2}$ for $t_{2} \leq t \leq t_{3}$ where $V_{c_{3}}=V_{g}-V_{o}$ and $V_{M_{3}}=-V_{c_{\max }}-V_{c_{3}}$

$\left(Z_{o} i_{L}\right)^{2}+\left(v_{c}-V_{c_{4}}\right)^{2}=V_{M_{4}}^{2}$ for $t_{3} \leq t \leq \frac{T_{S}}{2}$ where $V_{c_{4}}=-V_{o}$ and $V_{M_{4}}=V_{c_{\max }}-V_{c_{4}}$

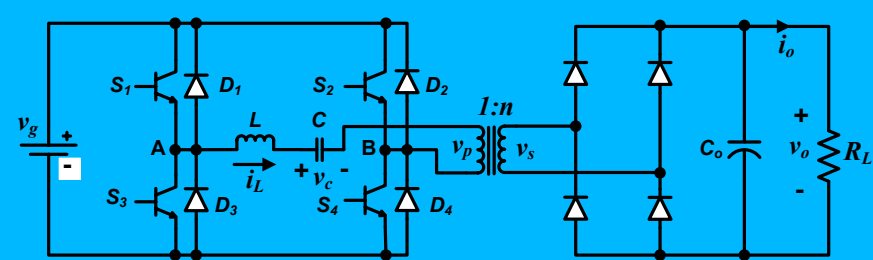

Fig.1. Full bridge SRC converter topology

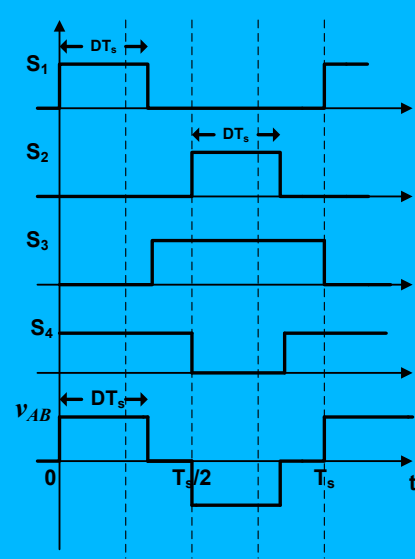

(a)

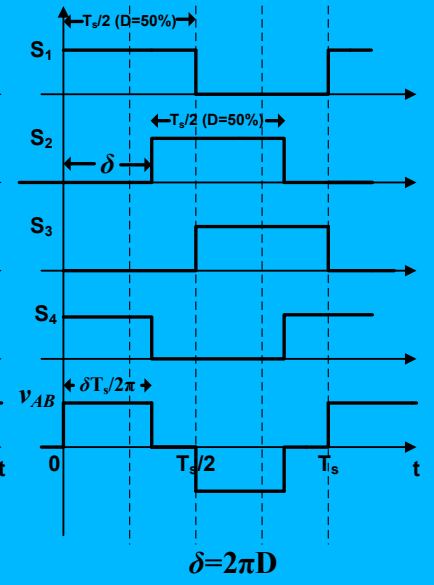

(b)
Fig.2. Gating signals for: (a) conventional duty-ratio control, and (b) phase shift modulation.

The steady state $v_{c}-i_{L}$ state-plane trajectories are shown in Fig.4 with $V_{c_{\max }}$ being the maximum voltage across the resonant capacitor $(C)$.

\section{DisCRETIZATION}

Normalizing all voltages and currents with respect to $V_{c_{\max }}$ and $V_{c_{\max }} / Z_{o}$ respectively yields

$$
i_{n L}=\frac{i_{L} Z_{o}}{V_{c_{\max }}}, v_{n C}=\frac{v_{c}}{V_{c_{\max }}}, v_{n o}=\frac{v_{o}}{V_{c_{\max }}}, v_{n g}=\frac{v_{g}}{V_{c_{\max }}}, f_{n s}=\frac{f_{s}}{f_{o}}
$$

Utilizing the half-wave symmetry of the waveforms in Fig.3a, the system is discretized as described in [4] and sampled every half switching period $\left(T_{s} / 2\right)$. The normalized discrete state-plane is shown in Fig.5. Taking the state variables as

$$
x_{1}=i_{n L}, \quad x_{2}=v_{n C}, \quad x_{3}=v_{n o}
$$

The discrete state-space representation of the system will take the form:

$x_{1}(k+1)=f_{1}\left(x_{1}(k), x_{2}(k), x_{3}(k), v_{n g}(k), f_{n s}(k), d(k)\right)=f_{1}(k)$

$x_{2}(k+1)=f_{2}\left(x_{1}(k), x_{2}(k), x_{3}(k), v_{n g}(k), f_{n s}(k), d(k)\right)=f_{2}(k)(7)$

$x_{3}(k+1)=f_{3}\left(x_{1}(k), x_{2}(k), x_{3}(k), v_{n g}(k), f_{n s}(k), d(k)\right)=f_{3}(k)$

Based on the geometry of the trajectory in Fig.5, and taking advantage of half-wave symmetry in Fig. 3a, it can be shown that the functions in (7) are given by

$f_{1}(k)=i_{n L}(k+1)=(-1)^{k}\left(\sqrt{i_{n L}^{2}(k)+\left(\left(v_{n o}(k)-v_{n C}(k)\right)(-1)^{k}\right)^{2}}\right) \mathrm{x}$

$\sin \left(\varphi(k)-\frac{\pi}{f_{n s}(k)}(0.5-d(k))\right)$ 


$$
\begin{aligned}
& f_{2}(k)=v_{n c}(k+1)=(-1)^{k}\left(\sqrt{i_{n L}^{2}(k)+\left(\left(v_{n o}(k)-v_{n c}(k)\right)(-1)^{k}\right)^{2}}\right) \mathrm{x} \\
& \cos \left(\varphi(k)-\frac{\pi}{f_{n s}(k)}(0.5-d(k))\right)-v_{n o}(k) \\
& f_{3}(k)=v_{n o}(k+1)=\frac{4 \tau-\frac{1}{f_{o} f_{n s}(k)}}{4 \tau+\frac{1}{f_{o} f_{n s}(k)}} v_{n o}(k)+\frac{4 R_{o} C}{4 \tau+\frac{1}{f_{o} f_{n s}(k)}} \mathrm{x} \\
& {\left[\left(2-v_{n C}(k)-v_{n c}(k+1)\right)(-1)^{k}\right]}
\end{aligned}
$$

where

$$
\begin{aligned}
& \varphi(k)=\cos ^{-1}[A], \tau=R_{o} C_{o} \\
& A=\frac{i_{n L}^{2}(k)+\left(v_{n o}(k)-v_{n C}(k)\right)^{2}+v_{n g}^{2}(k)-\left(1+v_{n g}(k)-v_{n o}(k)\right)^{2}}{2 v_{n g}(k) \sqrt{i_{n L}^{2}(k)+\left(\left(v_{n o}(k)-v_{n C}(k)\right)(-1)^{k}\right)^{2}}}
\end{aligned}
$$



(a)
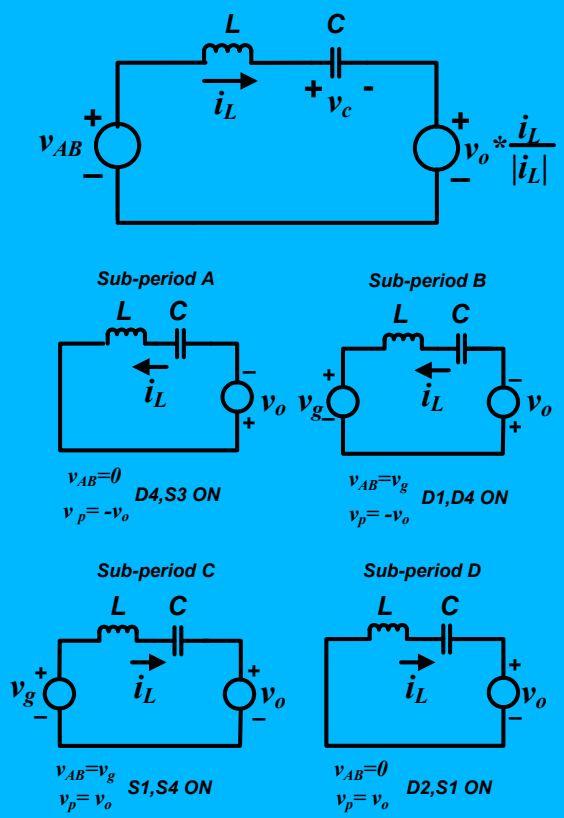

(b)

Fig.3. Continuous inductor current operation of full bridge PSM-SRC with half-wave symmetry: (a) waveforms, and (b) equivalent circuit diagrams for positive half-cycle sub-periods.

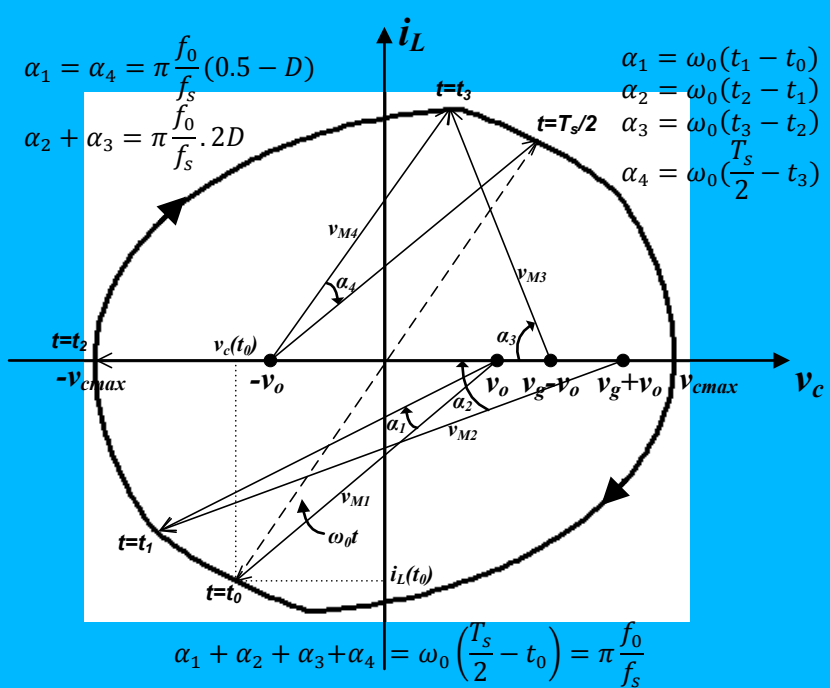

Fig.4. State-plane trajectory of full-bridge PSM-SRC.

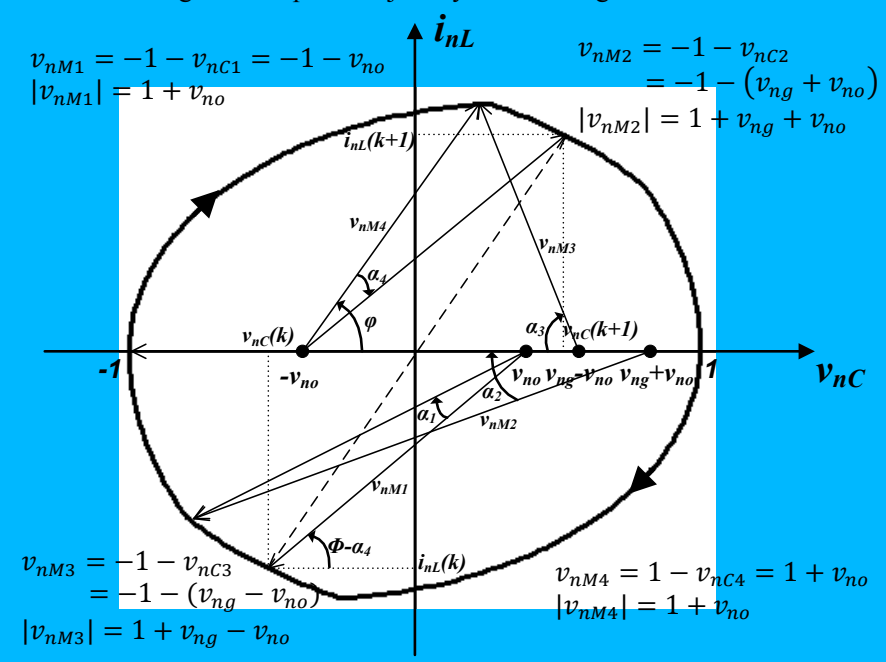

Fig.5. Normalized discrete state-plane trajectory of full-bridge PSM-SRC.

\section{SMALL-SIGNAL ANALYSIS AND MATRIX REPRESENTATION}

For the perturbed and linearized system around a specific steady-state operating point (considering perturbations in duty-ratio $\hat{d}(k)$ only), a general state-space format exists such that

$$
\begin{aligned}
& \hat{x}(k+1)=A_{0} \hat{x}(k)+B_{0} \hat{d}(k), k \text { even } \\
& \hat{x}(k+1)=A_{1} \hat{x}(k)+B_{1} \hat{d}(k), k \text { odd }
\end{aligned}
$$

Since the steady-state trajectories of the resonant states have symmetry about the origin (i.e. any two points on the steadystate trajectory are one half switching period apart with opposite polarity), therefore it is possible to derive a new discrete state-vector equation which can be updated every half-switching period. Equations (9) can be written in a general format

$$
\hat{x}(k+1)=A(k) \hat{x}(k)+B(k) \hat{d}(k)
$$

where

$$
\begin{gathered}
A(k)=P(k) A_{0} P(k) \\
B(k)=P(k) B_{0}
\end{gathered}
$$


Matrix $P(k)$ is a $3 \times 3$ matrix given by

$$
P(k)=\left[\begin{array}{ccc}
(-1)^{k} & 0 & 0 \\
0 & (-1)^{k} & 0 \\
0 & 0 & 1
\end{array}\right]
$$

Matrices $A_{0}$ and $B_{0}$ are defined, as given in [4], by using Taylor Series Expansion,

$$
\begin{gathered}
A_{0}=\left[\begin{array}{lll}
a_{11} & a_{12} & a_{13} \\
a_{21} & a_{22} & a_{23} \\
a_{31} & a_{32} & a_{33}
\end{array}\right]=\left[\begin{array}{lll}
\frac{\partial f_{1}(0)}{\partial x_{1}(0)} & \frac{\partial f_{1}(0)}{\partial x_{2}(0)} & \frac{\partial f_{1}(0)}{\partial x_{3}(0)} \\
\frac{\partial f_{2}(0)}{\partial x_{1}(0)} & \frac{\partial f_{2}(0)}{\partial x_{2}(0)} & \frac{\partial f_{2}(0)}{\partial x_{3}(0)} \\
\frac{\partial f_{3}(0)}{\partial x_{1}(0)} & \frac{\partial f_{3}(0)}{\partial x_{2}(0)} & \frac{\partial f_{3}(0)}{\partial x_{3}(0)}
\end{array}\right] \\
B_{0}=\left[\begin{array}{l}
b_{1} \\
b_{2} \\
b_{3}
\end{array}\right]=\left[\begin{array}{l}
\frac{\partial f_{1}(0)}{\partial d(0)} \\
\frac{\partial f_{2}(0)}{\partial d(0)} \\
\frac{\partial f_{3}(0)}{\partial d(0)}
\end{array}\right]
\end{gathered}
$$

Since the output voltage has even symmetry, it is constant and is not a function of $k$.

Although a unified discrete state-space representation is given by (10a), the system matrices $A(k)$ and $B(k)$ are a function of the $k^{\text {th }}$ half-switching period, i.e. the matrices change according to $k$. Constant matrices must be obtained to have a linear time-invariant system. Using a transformation

$$
\begin{gathered}
\hat{z}_{1}(k)=(-1)^{k+1} \hat{x}_{1}(k), \text { since } \hat{x}_{1}(0)<0 \\
\hat{z}_{2}(k)=(-1)^{k+1} \hat{x}_{2}(k), \text { since } \hat{x}_{2}(0)<0 \\
\hat{z_{3}}(k)=\hat{x}_{3}(k) \\
\hat{x}(k)=\left[\begin{array}{ccc}
(-1)^{k+1} & 0 & 0 \\
0 & (-1)^{k+1} & 0 \\
0 & 0 & 1
\end{array}\right] \hat{z}(k)=Q(k) \hat{z}(k)
\end{gathered}
$$

Replacing $k$ by $k+1$,

$$
\begin{aligned}
\hat{x}(k+1) & =\left[\begin{array}{ccc}
-1 & 0 & 0 \\
0 & -1 & 0 \\
0 & 0 & 1
\end{array}\right]\left[\begin{array}{ccc}
(-1)^{k+1} & 0 & 0 \\
0 & (-1)^{k+1} & 0 \\
0 & 0 & 1
\end{array}\right] \hat{z}(k+1) \\
& =R Q(k) \hat{z}(k+1)
\end{aligned}
$$

Substituting (12) and (13) into (10a) and taking into account $R R=I$ and $Q Q=I$,

$$
\begin{gathered}
R Q(k) \hat{z}(k+1)=A(k) Q(k) \hat{z}(k)+B(k) \hat{d}(k) \\
\hat{z}(k+1)=Q(k) R A(k) Q(k) \hat{z}(k)+Q(k) R B(k) \hat{d}(k) \\
\hat{z}(k+1)=A_{2} \hat{z}(k)+B_{2} \hat{d}(k)
\end{gathered}
$$

where

$$
\begin{gathered}
=\left[\begin{array}{lll}
-a_{11} & -a_{12} & a_{13} \\
-a_{21} & -a_{22} & a_{23} \\
-a_{31} & -a_{32} & a_{33}
\end{array}\right] \\
B_{2}=Q(k) R B(k)=\left[\begin{array}{l}
b_{1} \\
b_{2} \\
b_{3}
\end{array}\right]
\end{gathered}
$$$$
A_{2}=Q(k) R A(k) Q(k)=Q(k) R P(k) A_{0} P(k) Q(k)
$$

Notice that due to the transformation used in (11), $A_{2}$ and $B_{2}$ are constant matrices independent of sampling instant $k$.

Applying the $z$-transformation to (16), the small-signal frequency response of the converter, in the complex frequency domain, can be calculated using the relation $z=e^{s T_{S} / 2}$, which can be approximated by a bilinear transformation as in (18). The duty-ratio to output voltage transfer function is

$$
\frac{\hat{v}_{n o}(s)}{\hat{d}(s)}=\left.\left[\begin{array}{lll}
0 & 0 & 1
\end{array}\right]\left[z I-A_{2}\right]^{-1} B_{2}\right|_{z \approx \frac{1+T_{S} s / 4}{1-T_{S} s / 4}}
$$

Coefficients of the matrices $A_{2}$ and $B_{2}$ are derived by obtaining the partial derivatives in (10c) and (10d). These coefficients are expressed as

$$
\begin{aligned}
& a_{11}=\frac{V_{n M 1} \cos \left(\varphi-\alpha_{4}\right) \sin \left(\varphi-\alpha_{4}\right)}{\sin \varphi}\left(\frac{\cos \varphi}{V_{n M 1}}-\frac{1}{V_{n g}}\right)+\sin ^{2}\left(\varphi-\alpha_{4}\right) \\
& a_{12}=-\left[\frac{V_{n M 1} \cos ^{2}\left(\varphi-\alpha_{4}\right)}{\sin \varphi}\left(\frac{\cos \varphi}{V_{n M 1}}-\frac{1}{V_{n g}}\right)+\cos \left(\varphi-\alpha_{4}\right) \sin \left(\varphi-\alpha_{4}\right)\right] \\
& a_{13}=\frac{V_{n M 1} \cos \left(\varphi-\alpha_{4}\right)}{\sin \varphi}\left(\frac{\cos \varphi \cos \left(\varphi-\alpha_{4}\right)}{V_{n M 1}}-\frac{\cos \left(\varphi-\alpha_{4}\right)+\frac{V_{n M 3}}{V_{n M 1}}}{V_{n g}}\right)+\cos \left(\varphi-\alpha_{4}\right) \sin \left(\varphi-\alpha_{4}\right) \\
& a_{21}=-\frac{V_{n M 1} \sin { }^{2}\left(\varphi-\alpha_{4}\right)}{\sin \varphi}\left(\frac{\cos \varphi}{V_{n M 1}}-\frac{1}{V_{n g}}\right)+\cos \left(\varphi-\alpha_{4}\right) \sin \left(\varphi-\alpha_{4}\right) \\
& a_{22}=\frac{V_{n M 1} \sin \left(\varphi-\alpha_{4}\right) \cos \left(\varphi-\alpha_{4}\right)}{\sin \varphi}\left(\frac{\cos \varphi}{V_{n M 1}}-\frac{1}{V_{n g}}\right)-\cos ^{2}\left(\varphi-\alpha_{4}\right) \\
& a_{23}=-\frac{V_{n M 1} \sin \left(\varphi-\alpha_{4}\right)}{\sin \varphi}\left(\frac{\cos \varphi \cos \left(\varphi-\alpha_{4}\right)}{V_{n M 1}}-\frac{\cos \left(\varphi-\alpha_{4}\right)+\frac{V_{n M 3}}{V_{n M 1}}}{V_{n g}}\right)+\cos ^{2}\left(\varphi-\alpha_{4}\right)-1 \\
& a_{31}=-\frac{4 R_{o} C}{4 \tau+T_{s}} a_{21} \\
& a_{32}=-\frac{4 R_{o} C}{4 \tau+T_{s}}\left(1+a_{22}\right) \\
& a_{33}=\frac{4 \tau-T_{s}}{4 \tau+T_{s}}-\frac{4 R_{o} C}{4 \tau+T_{s}} a_{23} \\
& b_{1}=V_{n M 1} \frac{\pi}{F_{n s}} \cos \left(\varphi-\alpha_{4}\right) \\
& b_{2}=-V_{n M 1} \frac{\pi}{F_{n s}} \sin \left(\varphi-\alpha_{4}\right) \\
& b_{3}=\frac{4 R_{o} C}{4 \tau+T_{s}}\left[V_{n M 1} \frac{\pi}{F_{n s}} \sin \left(\varphi-\alpha_{4}\right)\right]
\end{aligned}
$$

Using the linear relation from Fig.2 $(\delta=2 \pi D)$, it follows that the small signal quantities are similarly related $(\hat{\delta}=$ $2 \pi \hat{d})$. Therefore the phase shift to output voltage transfer function can be derived from

$$
\frac{\hat{v}_{n o}(s)}{\widehat{\delta}(s)}=\frac{\hat{v}_{n o}(s)}{\hat{d}(s)} * \frac{1}{2 \pi}
$$

\section{CLOSED-LOOP PI CONTROL DESIGN}

In order to verify (19), closed-loop PI control design is according to the duty-ratio to output voltage transfer function in (18). Using this design, the closed loop control performance for both, conventional duty-ratio control and phase-shift control, is compared. The analogy of results proves the validity of (19).

\section{A. Duty-Ratio Control}

The typical structure of the closed-loop feedback control system for duty-ratio control of the SRC is shown in Fig.6. From Fig.6, the overall open-loop transfer function of the is

where

$$
T_{O L}(s)=T_{1}(s) T_{c}(s)
$$

$$
T_{1}(s)=\frac{\hat{v}_{o}(s)}{\hat{v}_{c}(s)}=\frac{\hat{v}_{o}(s)}{\hat{d}(s)} \frac{\hat{d}(s)}{\hat{v}_{c}(s)}=T_{p}(s) T_{m}(s)
$$

and $\quad T_{m}(s)=K_{1}=$ constant 


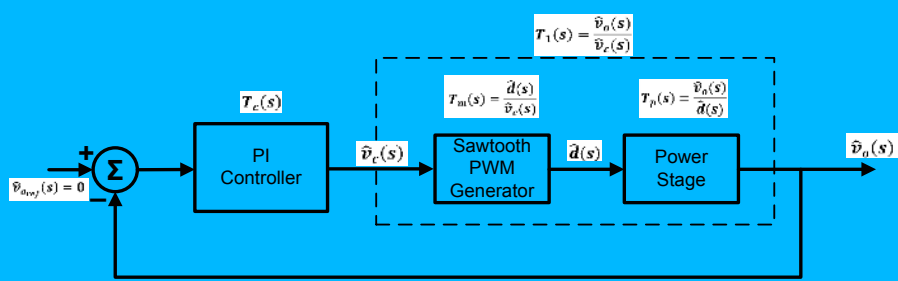

Fig.6. Feedback control structure for closed-loop duty-ratio control of SRC.

As explained in [23], for a given $T_{1}(s)$, the transfer function of the compensated amplifier $T_{c}(s)$ must be tailored so that $T_{O L}(s)$ meets the performance requirements expected of the power supply. These include, high dc gain to minimize steady-state error in power supply output and adequate phase margin to ensure system stability.

By selecting a steady-state operating condition (values in Table I), the small-signal transfer function in (18) can be computed as in (22). PI controller is then designed using Bode-plot (complex frequency) analysis and is given by (23). Fig.7 shows the open-loop Bode-plot before and after controller implementation. The integrator has lead to system dc gain improvement (necessary to reduce steady-state error) and the phase-delay is reduced leading to a faster dynamic response.

TABLE I

STEADY-STATE VALUES FOR SMALL-SIGNAL LINEARIZATION

\begin{tabular}{ccc} 
& Parameter & Value \\
\cline { 2 - 3 } & $V_{g}$ & $100 \mathrm{~V}$ \\
$L$ & $100 \mu \mathrm{H}$ \\
$C$ & $0.28 \mu \mathrm{F}$ \\
$Z_{o}$ & $18.85 \Omega$ \\
$F_{o}$ & $30 \mathrm{kHz}$ \\
$F_{s}$ & $40 \mathrm{kHz}$ \\
$D$ & 0.4 \\
$n$ & 1 \\
$C_{o}$ & $100 \mu \mathrm{F}$ \\
$R_{L}$ & $9.425 \Omega$ \\
$Q$ & 2 \\
$\frac{\hat{v}_{n o}(s)}{\hat{d}(s)}=\frac{-1358 s^{2}+2.173 * 10^{8} s-0.03474}{s^{3}+1.7 * 10^{5} s^{2}+1.828 * 10^{9} s+1.629 * 10^{12}}$ \\
$T_{c}(s)=16000\left(\frac{1+0.00079 s}{s}\right)$
\end{tabular}

\section{B. Phase-Shift Control}

The typical structure of the closed-loop feedback control system for SRC phase-shift control is shown in Fig.8. The same PI controller design is used, with the PSM-SRC cascaded with a gain of $2 \pi$ to mimic the duty-ratio controlled SRC. This makes use of (19) with the phase shift modulator acting as a gain, analogous to the saw-tooth PWM generator. Simulation results for both control methods are compared in the next section.

\section{RESULTS AND DISCUSSION}

A comparative time domain analysis of the closed loop duty-ratio controlled and PSM series resonant converter is performed using the detailed converter switching model and utilizing the controller in (23). Fig.9 shows simulation results for the SRC with both control techniques. The similarity in step response validates the derivation of the phase-shift to output voltage transfer function obtained from the duty-ratio to output voltage transfer function in (19).



Fig.7. Open loop bode plots



Fig.8. Feedback control structure for closed-loop PS control of SRC


(b)

Fig.7. Simulation results for SRC closed loop control: (a) Duty-ratio control, and (b) Phase-shift control. 


\section{CONCLUSION}

Discrete time domain modeling has been used to derive a linearized small-signal phase-shift to output voltage transfer function for the PSM-SRC. This is used for linear closed loop PI control design. The duty-ratio to output voltage transfer function for the duty-ratio controlled SRC was derived through state-plane analysis and discretization. A linear relationship exists between the phase-shift angle in the PSM technique and the actual duty-ratio in the PWM technique. This relation has been investigated and used to derive the phase-shift to output voltage transfer function, which shows similar response. Closed-loop controller design has been carried out to tune the PI controller parameters to the required step response. The designed controllers were applied to the non-linear switching model of the converter, obtaining satisfactory step response.

\section{REFERENCES}

[1] W. Zhang, P. Mao and Y. Liu, "Small-Signal Modelling of Series Resonant Converter," PEDS 2007, pp. 1466-1470.

[2] V. Vorperian, "Approximate Small-Signal Analysis of the Series and the Parallel Resonant Converters", IEEE Trans. on Power Electronics, vol. 4, no. 1, pp. 15-24, Jan. 1989.

[3] A.F.Witulski, A.F.Hernandez and R.W.Erickson, "Small Signal Equivalent Circuit Modeling of Resonant Converters," IEEE Trans. on Power Electronics, vol. 6, no. 1, pp.11-27, Jan. 1991.

[4] J. Batarseh and K.Siri, "Generalised Approach to the Small Signal Modelling of DC to DC Resonant Converters," IEEE Trans. on Aerospace Electronics System, vol.29, no.3, pp.894-909, July 1993.

[5] R.J. King and T.A. Stuart, "Small Signal Model of the Series Resonant Converters," IEEE trans. on Aerospace Electronics System, vol.21, no.3, pp.301-319, May 1985.

[6] V. Vorperian and S. Cuk, "Small-Signal Analysis of Resonant Converters," PESC 1983, pp. 269-282.

[7] M.G.Kim and M.J.Youn, "Discrete Time Domain Modeling and Analysis of Controlled Series Resonant Converter," IEEE Trans. on Industrial Electronics, vol.38, no.1, pp.32-40, Feb. 1991.

[8] M.G.Kim, D.S.Lee and M.J.Youn, "A New State Feedback Control of Resonant Converters," IEEE Trans. on Industrial Electronics, vol.38, no.3, pp.173-179, June 1991.
[9] M.G.Kim and M.J. Youn, "An Energy Feedback Control of Series Resonant Converter," IEEE Trans. on Power Electronics, vol. 6, no.3, pp. 338345, July 1991.

[10] J. Sosa, M. Castilla, L. Garcia de Vicuna, J. Matas and J. Miret, "Dynamic Analysis and Control Design of the Asymmetrical Clamped-Mode dcdc Series Resonant Converter", IECON 2006, pp. 2751-2756.

[11] B. S. Nathan and V. Ramanarayanan, "Analysis, Simulation and Design of Series Resonant Converter for High Voltage Applications," ICIT 2000, pp. 688-693.

[12] Y. Lu, K.W.E Cheng, S.L. Ho and J.F. Pan, "Passivity-Based Control of a Phase-Shifted Resonant Converter," IEE Proceedings-Electric Power Applications, vol. 152, issue 6, pp. 1509-1515, Nov. 2005.

[13] Y. Lu, K.W.E Cheng and S.L. Ho, "Quasi Current Mode Control for the Phase-Shifted Series Resonant Converter," IEEE Trans. on Power electronics, vol. 23, no. 1, pp. 353-358, Jan 2008.

[14] Z. Ye, P.K. Jain and P.C. Sen, "A Full-Bridge Resonant Inverter with Modified Phase-Shift Modulation for High Frequency AC Power Distribution Systems," IEEE Trans. on industrial electronics, vol. 54, no. 5, pp. 2831-2845, Oct 2007.

[15] F. Tsai, P. Materu and F.C. Lee, "Constant-frequency clamped-mode resonant converters," IEEE Trans. on power electronics, vol. 3, no. 4, pp. 460-473, Oct 1988.

[16] P. Imberston and N. Mohan, "Asymmetrical Duty Cycle Permits Zero Switching Loss in PWM Circuits with No Conduction Loss Penalty," IEEE Trans. on industry applications, vol. 29, no. 2, pp. 121-125, Jan/Feb 1993.

[17] P.K. Jain and A. St-Martin, "Asymmetrical Pulse-Width-Modulated Resonant dc/dc Converter Topologies," IEEE Trans. on power electronics, vol. 11, no. 3, pp. 413-422, May 1996.

[18] J. M. Burdio, F. Canales, P. M. Barbosa and F. C. Lee, “A Comparison Study of Fixed-Frequency Control Strategies for ZVS dc.dc Series Resonant Converters", PESC 2001, pp. 427-432.

[19] J. M. Burdio, L. A. Barragan, F. Monterde, D. Navarro and J. Acero, "Asymmetrical Voltage-Cancellation Control for Full-Bridge Series Resonant Inverters", IEEE Trans. on power electronics, vol. 19, no. 2, pp. 461468, March 2004.

[20] V.Agarwal, A.K.S.Bhat, "Small Signal Analysis of the LCC-Type Parallel Resonant Converter using Discrete Time Domain Modeling," IEEE Trans. on Industrial Electronics, vol.42, no.6, pp. 604-614, Dec. 1995.

[21] V.Agarwal, A.K.S.Bhat, "Large Signal Analysis of the LCC-Type Parallel Resonant Converter Using Discrete Time Domain Modeling," IEEE Trans. on Power Electronics, vo.10, no.2, pp. 222-238, March 1995.

[22] V.Agarwal, A.K.S.Bhat, "Dynamic Analysis of the Fixed-Frequency

PWM LCC-Type Parallel Resonant Converter using Discrete Time Domain Modeling," PESC'1996, pp. 272-278.

[23] Mohan, Undeland and Robbins, Power Electronics, Converters, Applications and Design, Third Edition, John Wiley \& Sons, Inc. 2003. 